\title{
SOBRE EL TEATRO DEL ABSURDO (DE JUAN DEL ENCINA A JUAN MATEU)
}

\author{
FRÉDÉRIC SERRALTA \\ Université de Toulouse-Le Mirail
}

Mucho habría que decir de la intensa actividad teatral que caracterizó a los medios del exilio republicano español, a raíz de la retirada de 1939 y del final de la segunda guerra mundial, en la ciudad francesa de Toulouse, y otro tanto de la extraordinaria trayectoria vital y creadora del valenciano Juan Mateu, que durante sus diez años de emigración (1957-1967) estrenó con gran éxito en la misma dos obras teatrales cuyos textos, después de largos decenios de olvido, están hoy publicados en sendas editoriales universitarias. Pero el presente artículo va a prescindir al respecto de cualquier información previa, que los lectores interesados podrán encontrar en los títulos citados en nota ${ }^{1}$, para centrarse directamente en el examen y comentario de un punto muy particular: la significativa persistencia, en una de las creaciones de Mateu -autodidacta impregnado de tradición oralde algunos mecanismos teatrales del absurdo cuyo lejano origen, aparentemente localizable en el teatro jocoso del XIX y principios del XX, se remonta en realidad a obras y actividades literarias nacidas en ámbitos intelectuales del Renacimiento y del Barroco.

Don Juan Tenorio "el refugiao»-que así se titula el aludido texto de Mateu - es un «drama cómico en cinco actos nada más, para no cansar al público» (sic) estrenado en Toulouse en 1958. Sus numerosas referencias concretas al mundillo español de dicha ciudad lo convierten en un verdadero documento histórico y sociológico, espejo minucioso de los anhelos, frustraciones, esperanzas y desilusiones de los exiliados republicanos, no

\footnotetext{
${ }^{1}$ Sobre el primer punto, véase F. SerRalta, «El teatro del exilio republicano español en Toulouse», en $A D E$ (Revista de la Asociación de Directores de Escena de España), Madrid, n. ${ }^{\circ}$ 98, noviembre-diciembre 2003, pp. 37-42. Sobre Juan Mateu, los estudios preliminares de las ediciones de sus obras Don Juan Tenorio, "el refugiao", Toulouse, Presses Universitaires du Mirail -5, allées A. Machado, 31058 Toulouse Cedex 9-, 1995, (Colección «Anejos de Criticón, n. ${ }^{\circ}$ 6), y El pasaporte, Toulouse, Éditions Hélios - 17, av. Winston Churchill, 31100 Toulouse-, 2001.
}

Rlit, LXVII, 133 (2005), 181-190 
sólo en Toulouse sino en toda Francia, y recuerdo fidedigno de lugares, actividades y figuras locales hoy lamentablemente barridas por el viento de la Historia. Pero es además, y diríamos que sobre todo, una divertidísima obra de teatro en la cual se parodia el original de Zorrilla con diversos procedimientos cómicos a cuál más absurdo y disparatado. En el escenario aparecen por ejemplo difuntos que sin embargo siguen hablando, personajes que mueren al ser heridos por una patada «envenenada», otros que entablan diálogos con el apuntador, actores que repentinamente intervienen en la ficción bajo su propio nombre... Esta enumeración, aunque rápida y muy incompleta, ya habrá llamado la atención de no pocos de nuestros conspicuos lectores, al menos de los que tengan noticias, por lecturas personales o por tradición oral, de las numerosas parodias decimonónicas del Tenorio o de La venganza de don Mendo, de Muñoz Seca, obra burlesca y paródica estrenada en 1918, muy celebrada en su tiempo y que se ha vuelto a representar con notable éxito no hace muchos años en los escenarios madrileños. Tratándose de una nueva parodia del drama de Zorrilla, no les parecerá nada extraño que el texto de Mateu reproduzca (aunque casi siempre matizándolos y enriqueciéndolos con un pequeño toque original) procedimientos que caracterizan al teatro burlesco del absurdo, el cual, según opiniones presuntamente autorizadas, nació en España a mediados del siglo XIX, con las refundiciones jocosas del Tenorio, y poco después alcanzó su auge con las «astracanadas» de Arniches y la obra citada de Muñoz Seca. Y no vamos a negar, desde luego, la presencia en estos últimos textos de recursos cómicos de la misma índole que los que muy brevemente acabamos de señalar en la obra de Mateu, y su muy probable influencia, a través de una tradición oral vehiculada por la memoria colectiva, en la creación de nuestro dramaturgo valenciano. Lo que sí pretendemos de paso poner en tela de juicio es la visión históricamente muy restrictiva, por ejemplo, de un Francisco García Pavón, cuando dice que Muñoz Seca «comienza, sin más ni menos, el teatro del absurdo. El teatro del disparate» ${ }^{2}$. La tradición teatral del disparate y del absurdo es en realidad muy anterior a Muñoz Seca y a los primeros parodistas del Tenorio, y los mecanismos jocosos de Juan Mateu hunden sus raíces en épocas más lejanas. Antes de ejemplificar y comentar la sorprendente persistencia en su obra de algunos recursos cómicos pluriseculares, permítasenos exponer, o al menos recordar brevemente a nuestros lectores mejor informados, el recorrido histórico de lo que llamaremos la tradición del absurdo teatral.

El disparate, la incoherencia con fines cómicos, emergió en las letras españolas, no en el teatro sino en la poesía, con los antaño tan celebrados y aludidos Disparates de Juan del Encina, insertos en su Cancionero que

${ }^{2}$ Citado por S. García CASTAÑEdA en la Introducción a su edición de La venganza de don Mendo, Madrid, Cátedra, 1994, p. 14. 
se publicó en Salamanca en $1496^{3}$. Derivados de la vieja «enumeración de imposibles» que ya aparece en la Égloga VIII de Virgilio, probablemente emparentados con las composiciones goliardescas de la literatura medieval ${ }^{4}$, contribuyeron a fomentar la difusión de las llamadas «coplas de disparates $»^{5}$ y junto con ellas empezaron a dar ejemplos, a lo largo del siglo XVI, de un humor absurdo, desligado de cualquier tipo de coherencia, tal vez no carente de trasfondo satírico pero destinado ante todo a provocar la risa con grotescas oposiciones o acumulaciones verbales ${ }^{6}$.

Existen indicios concordantes de que esta clase de humor disparatado se practicó y apreció al principio, y hasta ya entrado el siglo XVII, esencialmente en ámbitos cultos, entre eruditos y estudiantes universitarios, y sin salir del marco de la poesía jocosa. El injerto en el género dramático se realizó según parece en los primeros decenios del siglo XVII, no se sabe exactamente cuándo - aunque probablemente coincidiendo más o menos con el acceso al trono, en 1621, del rey Felipe IV - ni en qué circunstancias precisas - aunque aquí también es lícito suponer que pudo producirse en alguna academia cortesana cuando a unos ingenios acostumbrados a la «poesía de repente» se les ocurrió llevar a las tres jornadas de una comedia los incoherentes pero sabrosos placeres verbales de las viejas coplas de disparates, así como el jocoso, libre y disparatado espíritu de la mojiganga palaciega. El caso es que pronto empezaron a escribirse y representarse en $\mathrm{Pa}$ lacio, con ocasión de las fiestas de Carnestolendas y de San Juan, no pocas comedias burlescas, que bajo la misma denominación se fueron luego publicando, a partir de 1652, en colecciones como la de Comedias nuevas escogidas de los mejores ingenios de España. $\mathrm{Y}$ este subgénero dramático, muy olvidado durante siglos pero que recientemente ha merecido la atención de investigadores como Luciano García Lorenzo, Celsa Carmen García Valdés, Ignacio Arellano, Carlos Mata Induráin y el propio autor del presente estudio, fue el que verdaderamente vio nacer el teatro del absurdo.

No es ésta ocasión para demostrarlo recordando todas las características de la comedia burlesca, que encontrará el curioso lector analizadas en

\footnotetext{
${ }^{3}$ Se puede leer hoy el texto completo de los Disparates por ejemplo en Juan DEL ENCINA, Obras completas, Madrid, Espasa-Calpe, 1978 (Colección Clásicos Castellanos, n. ${ }^{\circ}$ 219), vol. II, pp. 8-16.

${ }^{4}$ Véase al respecto Blanca PerIÑán, Poeta ludens: disparate, perqué y chiste en los siglos XVI y XVII, Pisa, Giardini Editori, 1979.

5 Véase un análisis y algunas muestras de dicho subgénero en Maxime CHEVALIER y Robert JAMMES, «Supplément aux "coplas de disparates"», en Mélanges offerts à Marcel Bataillon par les hispanistes français, Bordeaux, Féret et fils, 1962, pp. 358-393.

${ }^{6}$ Citemos como ejemplo el principio de los Disparates de Juan del Encina: «Anoche de madrugada, / ya después de mediodía, / vi venir en romería / una nube muy cargada, / y un broquel con una espada / en figura de ermitaño [...]; vi venir un orinal / puesto de pontifical / como tres en un zapato; / y allí vi venir un gato / cargado de verdolagas...».
} 
algunos estudios de conjunto ${ }^{7}$. Bástenos señalar que, al pasar de la poesía al género dramático, en el cual es la acción al menos tan importante como la palabra, el absurdo exclusivamente verbal —que desde luego seguirá muy presente en el nuevo subgénero- se va forzosamente a completar con incoherencias situacionales y transgresiones visualizadas de la «normalidad» cotidiana del espectador. Otra consecuencia es la casi indispensable utilización de una base paródica: sólo basándose en historias, obras o anécdotas muy difundidas pueden permitirse los autores de comedias burlescas disparatar libremente sin que sus devaneos desconecten al público de una intriga ya conocida de antemano. Chistes, juegos e incoherencias verbales, situaciones ilógicas y disparatadas, base paródica... En la comedia burlesca del siglo XVII, como muy claramente lo intuyó Miguel Artigas en un estudio pionero ${ }^{8}$, está ya todo el teatro jocoso -incluido el de Muñoz Secade fines del XIX y principios del XX, cuyos autores, aun sin conocimiento directo de sus fuentes, las vinieron reutilizando a partir de una subterránea pero muy probablemente ininterrumpida transmisión oral.

Efectivamente, si hoy nos parece que las estrecheces académicas del siglo XVIII no dejarían mucho espacio para la perennización del absurdo teatral nacido en el siglo anterior, existen no pocos indicios - tales como la composición atribuida al fabulista Tomás de Iriarte de textos asimilables a las viejas «coplas de disparates», la publicación, en las muy difundidas y leídas colecciones de «sueltas», de no pocas comedias burlescas del XVII', y sobre todo la índole claramente paródica y disparatada de varios sainetes del popular Ramón de la $\mathrm{Cruz}^{10}$ - de que la afición a un humor absurdo, nacida como queda dicho en círculos eruditos, siguió difundiéndose entre un público menos selecto y afincándose cada vez más en el género teatral.

Género en el cual quedó definitivamente instalada la tradición del absur-

\footnotetext{
${ }^{7}$ Por ejemplo en F. SeRralta, «La comedia burlesca: datos y orientaciones», en Risa y sociedad en el teatro español del Siglo de Oro (Actes du IIIe colloque du G.E.S.T.E., 31 janvier-2 février 1980), Paris, Éditions du CNRS, 1980, pp. 99-129, o Ignacio AREllano, «La comedia burlesca», en J. MENÉNDEZ PELÁEZ (coord.), Historia de la literatura española, León, Editorial Everest, 1993, II (Renacimiento y Barroco), pp. $492-496$.

${ }^{8}$ Editando una comedia burlesca del XVII en el Boletín de la Biblioteca Menéndez y Pelayo, VIII, 1926, escribía Miguel ARTigAS, p. 59: «Para algunos será además esta comedia en chanza una revelación, pues echarán de ver que los trucos, ardides y retorcimientos de que se valen ciertos dramaturgos contemporáneos son ya muy viejos».

${ }^{9}$ Por lo menos El caballero de Olmedo, Durandarte y Belerma, El rey don Alfonso el de la mano horadada, Los siete infantes de Lara y El desdén con el desdén.

${ }^{10}$ En la Introducción a su edición citada de La venganza de Don Mendo escribe Salvador GARCÍA CASTAÑEDA, p. 18, «Manolo, «tragedia para reír o sainete para llorar», Inesilla la de Pinto, "sainete trágico», y trasunto burlesco de la Inés de Castro, El Muñuelo, «tragedia por mal nombre», y Zara, «tragedia en menos de un acto», que parodia Zaire de Voltaire. Todas ellas, y otras más, son obra de don Ramón de la Cruz, quien no perdía ocasión de atacar a la tragedia neoclásica con las armas del ridículo».
} 
do a raíz de la verdadera explosión parodística que se produjo a partir de 1846, con las primeras imitaciones burlescas del Tenorio, se extendió durante la segunda mitad del siglo con el auge del llamado «género chico», y dio lugar en los primeros decenios del Xx a obras de tanto éxito como las de Arniches o Muñoz Seca. Pero aquí no vamos a decir más de este período, por ser el más conocido y contar con valiosos estudios de conjunto $^{11}$. Nos atendremos a este breve repaso de la larga y vieja trayectoria del absurdo teatral, y preferiremos ahora, con el fin de ilustrar la impresionante persistencia de una tradición tan añeja, volver a la obra de Mateu y evocar algunos de sus procedimientos cómicos - saltando en cierto modo por encima de sus más inmediatos antecedentes en las populares parodias decimonónicas del drama de Zorrilla- para equipararlos directamente con sus fuentes más lejanas.

En lo que concierne a la comicidad verbal, citemos primero en el Don Juan Tenorio «el refugiao» de Mateu el disparate más sencillo - y al mismo tiempo de más rancio abolengo, característico de una tradición oral directamente fundada en los Disparates de Juan del Encina. Nos referimos al que presenta como unidas dos realidades aparentemente contradictorias y excluyentes una de otra (o, al contrario, como contradictorias las que normalmente son muy compatibles), aquél que todavía en nuestros días da pie a canciones y juegos de niños o a textos jocosos como los «cuentos de mentiras» o el que empieza «Era de noche, y sin embargo llovía...». Se podrían citar varios ejemplos, tales como «Prepara dos gaseosas, / pero que sean bien fuertes» (Acto I, vv. 175-76), o «Y por las noches, mi diosa, I a tomar el sol hermoso, / ese sol tan delicioso / que hace aquí en la Villa rosa» (V, vv. 3282-85).

En este mismo campo es digno de mención un tipo de chiste muy particular que reproduce una estructura verbal característica, esta vez, de las comedias burlescas del siglo XVII, y que tiene sus remotos orígenes en los libros de cuentecillos y agudezas del XVI. Se trata de lo que en una ocasión llamamos el «chiste-enigma» ${ }^{12}$, chiste construido como una adivinanza y que consta de tres fases sucesivas: primero, una afirmación sorprendente e incluso totalmente ilógica, después, como reacción normal del interlocutor (y supuestamente del público), una réplica que expresa incredulidad o pide aclaraciones, y, por último, la explicación, exclusivamente fundada en un doble sentido. Veamos un ejemplo sencillo sacado de una burlesca del XVII:

11 Véase por ejemplo Francisca ÍñIGUEZ BARRENA, La parodia teatral en España (1868-1914), Sevilla, Universidad, 1999, y, sobre las imitaciones del Tenorio hasta ya entrado el siglo XX, Carlos SERrano (ed.), Carnaval en noviembre. Parodias teatrales españolas de Don Juan Tenorio, Alicante, Instituto de Cultura Juan Gil Albert, 1996.

${ }^{12}$ Véase F. SERRALTA, «El chiste-enigma en la comedia burlesca del siglo XVII», en Tigre, Grenoble, Université Stendhal, n. ${ }^{\circ}$, 1991, pp. 83-92. 


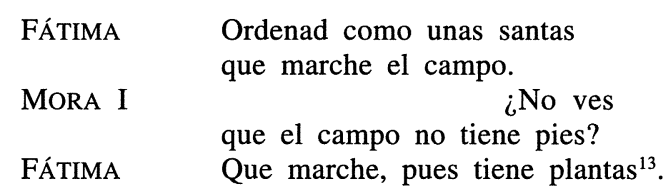

El chiste de Don Juan Tenorio «el refugiao» que vamos a citar ahora es más denso, ya que se funda en el doble sentido no de una sino de dos palabras («mar» $\mathrm{y}$ «golfos»), pero funciona exactamente de la misma manera. Entre los monumentos y lugares notables de Madrid, incluye el personaje del escultor «una playa», prosiguiendo así el diálogo:

$\begin{array}{ll}\text { JUAN } & \text { ¿Playa en Madrid? ¡Si no hay mar! } \\ \text { ESCULTOR } & \text { ¿Que allí no hay mar? ¡Anda, vamos! } \\ & \text { Tenemos la mar... de vagos, } \\ & \text { os lo puedo asegurar. } \\ \text { JUAN } & \text { Sí, que hay mares especiales: } \\ & \text { allí no hay cabos, ni costas... } \\ & \text { pero están los principales } \\ & \text { golfos de España. }\end{array}$

ESCULTOR ¡Y de Europa! (V, vv. 3139-3146)

Como se ve, el ejemplo es significativo a la vez de la permanencia de un viejo mecanismo cómico y de la manera peculiar que tiene Mateu de remozarlo, en este caso con fines satíricos.

Otro importante factor de comicidad verbal en Don Juan Tenorio «el refugiao» es el anacronismo, el desfase, la mezcla incoherente de períodos, niveles de lengua y planos diferentes que son la base misma del disparate desde su primera aparición en la literatura y la escena. La misma libertad creadora que en la comedia burlesca del XVII se traducía por constantes transgresiones del decoro, tales como la ridícula presentación de personajes reales ${ }^{14}$ o la jocosa confusión entre las religiones católica y musulma$\mathrm{na}^{15}$, es la que fundamenta la transposición por Mateu del drama de Zorrilla. Para demostrarlo cumplidamente sería preciso citar toda la obra, pero se comprenderá que el mero hecho de adaptar la conocida historia de don Juan al ambiente de los refugiados en Toulouse ya es una fuente inagotable de anacronismos, y el choque entre los casi míticos episodios del drama original y las realidades cotidianas del exilio surte un efecto cómico de índole genuinamente «disparatada». Ver que a don Juan Tenorio le vienen a

\footnotetext{
${ }^{13}$ La renegada de Valladolid, de Monteser, Solís y Silva, en Comedias burlescas del Siglo de Oro, III, Universidad de Navarra-Iberoamericana-Vervuert, 2002, vv. 10851088. El chiste se funda por supuesto en el doble sentido de la palabra «plantas».

${ }_{14}$ Por ejemplo, en toda la tercera jornada, el rey de El caballero de Olmedo, de Francisco Antonio de Monteser.

${ }^{15}$ Se puede ver al respecto F. Serralta, «La religión en la comedia burlesca del siglo XVII», en Criticón, Toulouse, France-Ibérie Recherche, n. ${ }^{\circ} 12$, 1980, pp. 55-76.
} 
detener dos «gendarmes» franceses y le llevan directamente a «San Michel» - la cárcel de la ciudad- (I, vv. 984-987), que la alcahueta Brígida viaja montada en una bicicleta con «un sillín roto..., sin pedales, sin farol...» (IV, vv. 2297-2301), o, inmediatamente después de oírle hablar con un anticuado y ampuloso voseo, escuchar en boca de don Luis Mejía, dirigida a su criado, una orden de tono sumamente familiar («iVen pacá!», I, v. 858), todo ello entronca directamente con los más antiguos recursos del absurdo teatral.

En cuanto a los procedimientos más propiamente escénicos, y no ya verbales, de la obra de Mateu, también es evidente su frecuente raigambre tradicional. Sin pretender realizar un estudio exhaustivo, citaremos rápidamente al respecto las constantes rupturas de la ilusión teatral, tales como los apartes dirigidos al público ${ }^{16}$, tan característicos del comportamiento de los graciosos en la Comedia del siglo XVII, o la irrupción de los actores, con su propio nombre, entre los personajes de la ficción ${ }^{17}$, practicada ya durante el mismo siglo por ejemplo en las loas de presentación de las compañías; rupturas que en Don Juan Tenorio «el refugiao» llegan a extremos muy divertidos, con juegos escénicos relacionados con el apuntador ${ }^{18}$ que ya tenían antecedentes directos en obras paródicas del XIX y principios del $\mathrm{XX}$, en las cuales la salida del apuntador a las tablas vino a ser, según fuentes orales y también no pocos testimonios escritos, un casi obligatorio procedimiento jocoso. Estas relaciones de parentesco con los recursos escénicos del teatro anterior, así evocadas muy por encima, las vamos ahora a ilustrar algo más detenidamente con dos ejemplos precisos, centrados primero en la utilización de accesorios burlescos y luego en el tratamiento jocoso de los «muertos-vivos».

El empleo de accesorios burlescos o fuera de proporción con la realidad que pretenden ilustrar es un procedimiento que comparte Mateu con sus lejanos antecedentes de la comedia burlesca del XVII. Las hiperbólicas dimensiones, según la acotación original de Mateu, de la carta que escribe don Juan en el acto I («Saca una carta como una sábana», I, después del v. 111), proceden de la misma ampliación burlesca que en Céfalo y Pocris, de Calderón, ilustra el príncipe Rosicler cuando, enamorado de una dama, «saca un zapato muy grande» y lo presenta con estas palabras:

${ }^{16}$ Comentario de un personaje ante el «despiste» de otro: «Éste no ha visto el $\mathrm{Te}$ norio» (I, v. 539).

17 Como por ejemplo cuando, en medio de una escena muy tensa, dice de repente el actor que representa el papel de don Gonzalo: «Soy yo, el amigo Florista, / que estoy haciendo teatro» (V, vv. 3655-3656).

${ }^{18}$ Un ejemplo cuando, al principio de la famosa escena del sofá, el personaje de don Juan repite varias veces, como si se le hubiera olvidado el papel, el verso «¡Doña Inés del alma mía!», hasta que se dirige al apuntador diciéndole: «iMaldita sea tu tía! / Pero ¿me apuntas, o no?» (IV, v. 2465-2466). 


$$
\begin{aligned}
& \text {...............ésta es la concha } \\
& \text { de aquesta perla: advertid } \\
& \text { cómo la perla será } \\
& \text { cuando la concha es así, } \\
& \text { y si así huele el zapato } \\
& \text { cómo olerá el escarpín }{ }^{19} \text {. }
\end{aligned}
$$

De la misma manera, la «espada de juguete» que en la obra de Mateu (II, acotación después del v. 1402) desenvaina don Luis Mejía es una clara derivación de los caballitos de juguete en que a veces salen montados los personajes de tal o cual comedia burlesca del XVII, o de otros ridículos accesorios utilizados con frecuencia en las piezas paródicas de dicho siglo, como por ejemplo cuando en Durandarte y Belerma, cumpliendo su fúnebre misión, arranca Montesinos a Durandarte el corazón, «el cual corazón», según la acotación contemporánea, «será una pata de vaca» ${ }^{20}$.

En cuanto a la repetida presencia, en Don Juan Tenorio "el refugiao», de personajes que después de muertos siguen hablando y actuando, era un recurso también frecuente en la vieja comedia burlesca: disparate elemental, por supuesto, que se explota de diversas maneras con el fin común de provocar la risa. Por ejemplo, en El caballero de Olmedo, de Monteser, el personaje central, ya muerto, se queja de sus asesinos ante el rey y declara:

$$
\begin{aligned}
& \text { Y viendo que de la muerte } \\
& \text { soy la más cercana parte, } \\
& \text { en virtud de un poder mío } \\
& \text { he venido a querellarme. } \\
& \text { Justicia, justicia pido, } \\
& \text { y ya que tú no los mates, } \\
& \text { denme hacienda en la otra vida } \\
& \text { para poder sustentarme }{ }^{21} \text {. }
\end{aligned}
$$

En la obra de Mateu hablan así después de muertos, tal vez con mayor verosimilitud en razón del trasfondo sobrenatural del drama parodiado, tanto Doña Inés como el comendador Don Gonzalo. Una intervención póstuma de este último, diferente de la que desde El burlador de Sevilla da pie al castigo final de Don Juan, merece un breve comentario, ya que nos parece una buena muestra de las dotes cómicas del autor. Está Don Juan Tenorio «el refugiao» arrodillado ante las estatuas de sus víctimas (en la representación, los actores más o menos empolvados) y solicitando enfáticamente el perdón de doña Inés. Pero resulta que por descuido ha quedado de rodillas ante la estatua de Don Gonzalo. Sigilosamente le indica ésta, con un

\footnotetext{
${ }^{19}$ En Comedias burlescas del Siglo de Oro (ed. I. Arellano, C.C. García Valdés, C. Mata y M.C. Pinillos), Madrid, Espasa Calpe, 1999 (Colección Austral, n. ${ }^{\circ}$ 463), p. 400, vv. 1831-1836.

${ }^{20}$ Citado en F. SerRalta, «La comedia burlesca...», p. 107.

${ }^{21}$ En Comedias burlescas... (ed. cit. en la nota 19), p. 183, vv. 1645-1652.
} 
gesto de la mano, que se ha equivocado de estatua... Don Juan, que no lo ha visto, prosigue:

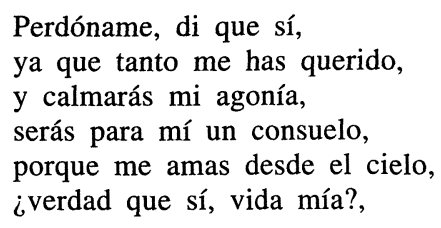

interrumpiéndole repentinamente la siguiente respuesta del Comendador:

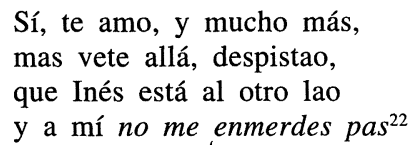

Como se puede apreciar, sobre una base tradicional, la de los muertosvivos, se construye aquí una explotación original marcada por la fuerza cómica que en ésta y otras ocasiones manifiesta el autor.

Pero nuestro propósito final no es insistir en los méritos de su obra, de los cuales habría muchas más cosas que decir, ni desde luego afirmar que sus procedimientos cómicos están desvinculados de las anteriores parodias del drama de Zorrilla, con las que por supuesto tiene también mucha relación este Don Juan Tenorio «el refugiao». Lo que sí pretendemos dejar patente es la impresionante vigencia de una tradición secular que permitió en 1958 a un autodidacta valenciano, lejos de su tierra, de lecturas eruditas y modelos directos, empalmar con gloriosos antepasados y llevar a las tablas del exilio un sentido del absurdo y del disparate que desde el venerable y algo olvidado Juan del Encina ha venido a ser en nuestros días - pero esto ya merecería un estudio aparte- un componente esencial de lo que se podría llamar el humor «a la española».

${ }^{22}$ V, vv. 3244-3253. No me enmerdes pas: calco de una trivial expresión francesa que se podría traducir por «no me fastidies». 
FRÉDÉRIC SERRALTA

\title{
RESUMEN
}

Sobre el teatro del absurdo (de Juan del Encina a Juan Mateu), por Frédéric Serralta.

A partir del análisis de algunos mecanismos cómicos del absurdo en Don Juan Tenorio «El refugiao» - obra paródica del dramaturgo exiliado Juan Mateu estrenada en Toulouse en 1958-, el artículo pretende demostrar la persistencia de una tradición que no se remonta sólo a La venganza de don Mendo de Muñoz Seca (el cual no fue ni mucho menos, como demasiadas veces se ha dicho, el inventor del teatro del absurdo), sino que se inscribe en una vieja trayectoria arraigada en los famosos Disparates de Juan del Encina, ilustrada luego por la comedia burlesca del siglo XVII, patente en la afición popular del XIX y principios del XX al teatro paródico y que todavía hoy es una de las fuentes de lo que se podría llamar un humor «a la española».

Palabras clave: Teatro del absurdo. Comedia burlesca del XVII. Mateu (Juan).

\begin{abstract}
From the analysis of a few comic devices of the absurd in Don Juan Tenorio «El refugiao» - a parodical play by exiled playwright Juan Mateu, first performed in Toulouse in 1958-, this article aims at showing that a tradition is still alive - a tradition that can, non only be traced back to La venganza de don Mendo by Muñoz Seca (who did not, as has been claimed, invent the theatre of the absurd), but which is also part of an old trend stemming from Juan del Encina's famous Disparates, which has been exemplified by the burlesque plays of the seventeenth century, which was obvious in the nineteenth and early twentieth century popular liking for parodical drama, and which is still today one of the sources of what could be called humour the Spanish way.
\end{abstract}

Key words: Theatre of the absurd. Burlesque plays of XVIIth century. Mateu (Juan). 